\title{
Collecting duct carcinoma of the kidney: an immunohistochemical study of I I cases
}

\author{
Andrea Vecchione ${ }^{1,2}$, Tommaso Prayer Galetti ${ }^{3}$, Marina Gardiman 4 , \\ Hideshi Ishii ${ }^{5,6}$, Enrico Giarnieri ${ }^{1,2}$, Francesco Pagano ${ }^{3}$, Leonard G Gomella1, \\ Carlo M Croce ${ }^{5}$ and Raffaele Baffa*
}

\begin{abstract}
Address: ${ }^{1}$ Department of Urology, Kimmel Cancer Center, Thomas Jefferson University, 1025 Walnut Street, Philadelphia, PA, 19107, USA, ${ }^{2}$ University of Rome "La Sapienza", Ospedale Santo Andrea, Rome, Italy, ${ }^{3}$ Department of Urology, University of Padova, Via Giustiniani 25 , Padova, Italy, ${ }^{4}$ Department of Pathology, University of Padova, Via Gabelli 3, Padova, Italy, ${ }^{5}$ Department of Microbiology/Immunology, Kimmel Cancer Center, Thomas Jefferson University, 220 10th South Street, Philadelphia, PA, 19107, USA and ${ }^{6}$ Jichi Medical School, Center for Molecular Medicine, Division of Stem Cell Regulation/Molecular Hematopoiesis, 3311-1 Yakushiji, Minami-Kawachi, Tochigi, 329-0498, Japan

Email: Andrea Vecchione - a_vecchione@mail.jci.tju.edu; Tommaso Prayer Galetti - Tommaso.Prayer@unipd.it; Marina Gardiman - marinapaola.gardiman@sanita.padova.it; Hideshi Ishii - H_Ishii@mail.jci.tju.edu;

Enrico Giarnieri - Enrico.Giarnieri@uniroma1.it; Francesco Pagano - Francesco.Pagano@sanita.padova.it;

Leonard G Gomella - Leonard.Gomella@jefferson.edu; Carlo M Croce - Carlo.Croce@jefferson.edu; Raffaele Baffa* - R_Baffa@mail.jci.tju.edu

* Corresponding author
\end{abstract}

Published: 09 September 2004

BMC Urology 2004, 4:II doi:10.1 186/147I-2490-4-1।
Received: 20 March 2004

Accepted: 09 September 2004

This article is available from: http://www.biomedcentral.com/I47I-2490/4/II

(c) 2004 Vecchione et al; licensee BioMed Central Ltd.

This is an open-access article distributed under the terms of the Creative Commons Attribution License (http://creativecommons.org/licenses/by/2.0), which permits unrestricted use, distribution, and reproduction in any medium, provided the original work is properly cited.

\begin{abstract}
Background: Collecting duct carcinoma (CDC) is a rare but very aggressive variant of kidney carcinoma that arises from the epithelium of Bellini's ducts, in the distal portion of the nephron. In order to gain an insight into the biology of this tumor we evaluated the expression of five genes involved in the development of renal cancer (FEZI/LZTSI, FHIT, TP53, P27kipl, and BCL2).

Methods: We studied eleven patients who underwent radical nephrectomy for primary CDC. All patients had an adequate clinical follow-up and none of them received any systemic therapy before surgery. The expression of the five markers for tumor initiation and/or progression were assessed by immunohistochemistry and correlated to the clinicopathological parameters, and survival by univariate analysis.

Results: Results showed that FezI protein expression was undetectable or substantially reduced in 7 of the II (64\%) cases. Fhit protein was absent in three cases (27\%). The overexpression of p53 protein was predominantly nuclear and detected in 4 of II cases (36\%). Immunostaining for p27 was absent in 5 of II cases (45.5\%). Five of the six remaining cases (90\%) showed exclusively cytoplasmic protein expression, where, in the last case, p27 protein was detected in both nucleus and cytoplasm. Bcl2 expression with $100 \%$ of the tumor cells positive was observed in 4 of II (36\%) cases. Statistical analysis showed a statistical trend $(P=0.06)$ between loss and reduction of FezI and presence of lymph node metastases.
\end{abstract}

Conclusions: These findings suggest that Fezl may represent not only a molecular diagnostic marker but also a prognostic marker in CDC. 


\section{Background}

Renal cancer accounts for 3\% of adult malignancies. An estimated 35,710 new cases are expected to occur in the U.S. in the current year and 12,480 patients will die of this disease [1]. The majority of renal cancers arises from the proximal tubular epithelium, with a characteristic clear or granular cell appearance by light microscopy, and is referred to as renal cell carcinoma (RCC).

Recent evidence suggests that solid renal parenchymal tumors arising in the distal portion of the nephron, such as oncocytomas, chromophobe renal cell carcinomas and collecting duct carcinomas represent an heterogeneous group of neoplasm from both clinical and biological perspectives [2]. Collecting duct carcinoma (CDC), also known as Bellini duct carcinoma, is a rare but highly aggressive renal neoplasm arising from the distal portion of the nephron, and represents approximately $2 \%$ of all the RCCs [3,4]. Clinically, CDC appears as a renal mass often accompanied by flank pain and hematuria and is frequently mistaken for RCC or transitional cell carcinoma of the renal pelvis $[3,5,6]$. CDC, however, can be identified based on gross, microscopic, histochemical, and immunohistochemical features. Macroscopically, CDCs are often located at the confluence of the medulla and renal pelvis, and show a characteristic gray-white-tan color, with absence of foci of necrosis and hemorrhage [7]. Histologically, CDC presents a tubulo-papillary morphology, often accompanied by desmoplasia, atypia in collecting ducts, and intratubular spread [7], features rarely seen in RCC.

Histochemically, CDC cells contain intracytoplasmic mucicarminophilic material, where RCCs do not [7]. CDCs are also positive by immunohistochemical staining with high-molecular-weight keratin and lectin, proteins typically expressed in the epithelium of the distal tubules $[8,9]$. Conversely, almost all other renal carcinomas express antigens widely expressed in the cells of the proximal tubules, such as low molecular weight cytokeratins and vimentin [9]. Although little is known about the genetic profile of CDCs, a DNA flow cytometry study has demonstrated aneuploidy in $90 \%$ of these tumors [5], and cytogenetics has shown frequent monosomy of chromosomes $1,6,8,14,15$, and $22[10,11]$.

Loss of heterozygosity (LOH) analysis in six CDCs revealed allelic loss at chromosomes $8 p$ and $13 q$ in $50 \%$ of the tumors, and rarely at the short arm of chromosome $3[12,13]$. This data suggests that distinct genetic alterations from those observed in RCC, in which $3 \mathrm{p} \mathrm{LOH}$ is common [14], occur in the development of this rare renal tumor.
To improve our understanding of the biology of CDC and to explore the possibility that different genes may be involved in the etiology and prognosis of this neoplasm, we analyzed by immunohistochemistry eleven cases of CDC for the expression of five genes (Fez1, Fhit, p53, p27, and bcl2) often involved in the development of many common cancers. These findings were correlated with conventional clinical-pathological features including clinical outcome.

\section{Methods \\ Patients}

Eleven patients with primary CDC (two women and nine men; age range 40 to 84 years, mean 62) underwent radical nephrectomy between 1983 and 2000 in the Department of Urology, University of Padua, Italy. Tissue specimens from these tumors were registered in the Department of Pathology at the same institution. All eleven patients had an adequate clinical follow up and were included in our study. Eight of the 11 patients had metastatic disease, five with lymph node metastasis and five with distant metastases at the time of surgery. None of these eleven patients received any systemic therapy before surgery. Samples were fixed in 10\% buffered formalin for routine histological processing and were stained with hematoxylin and eosin.

\section{Pathological study}

Immunohistochemical reactions using anticytokeratin (Keratins 5, 8, 10, an 18) monoclonal antibodies, and Ulex Europaeus Lectin, polyclonal antibody were performed as previously described [15]. The tumors were classified histologically according to standardized criteria [3,5-7] and staged according to the guidelines of the tumor-node-metastasis (TNM) classification of malignant tumor [16].

\section{Immunohistochemistry}

Paraffin sections containing non-neoplastic kidney as well as neoplastic areas were deparaffinized according to standard procedures followed by rehydration through graded ethanol series, and mounted on positively charged slides. Immunostaining was performed as previously described [17]. Briefly for Fez1, Fhit, p53, and p27 immunostaining, slides were immersed in citrate buffer $[0.01 \mathrm{M}$ sodium citrate (pH6.0)] and heated in a microwave oven at $600 \mathrm{~W}$ (three times for $5 \mathrm{~min}$ each) to enhance antigen retrieval. For retrieval of $\mathrm{Bcl} 2$ oncoprotein, we used the target retrieval solution, high $\mathrm{pH}$ from DAKO (Carpinteria, CA, USA) per manufacturers instructions. The primary antibodies used in this study were: anti-Fez1 rabbit polyclonal antibody [17], anti-Fhit rabbit polyclonal antibody (Zymed Laboratories, San Francisco, CA) at 1:1,000 dilution, anti-p53, anti-p27, anti-Bcl2 (DAKO, Carpinteria, CA, USA) at dilution of 1:25, 1:50, and 1:40 respectively, 
as specified by the manufacturers. The primary antibodies were omitted and replaced with pre-immune serum in the negative controls. Sections were reacted with biotinylated anti-rabbit or anti mouse antibodies and streptavidinbiotin-peroxidase (Histostain-SP Kit; Zymed laboratories, San Francisco, CA). Diaminobenzidine (DAB) was used as a chromogen substrate to visualize staining. Finally, sections were washed in distilled water and weakly counterstained with Harry's modified hematoxylin. The immunostaining was evaluated by two pathologists in a blinded fashion (A.V.; R.B.). For statistical analysis, cases were scored as positive if they had more than $20 \%$ (p53) or more than $40 \%$ (Fez1 and p27) of positive cells. Fhit and bcl 2 cases showed either all positive or all negative cells and were scored accordingly.

\section{Statistical analysis}

We evaluated the association between each marker's expression (positive or negative) and each clinical-pathological outcome (metastasis and stage) with Fisher's exact test. For survival, we used the Kaplan-Meier method and log-rank test, as well as Cox proportional hazards regression.

\section{Results}

Pathological study

All cases showed several common microscopic features. The main tumor consisted of a tubulo-papillary carcinoma showing pleomorphism and a high mitotic rate with several bizarre mitotic figures, and presence of small cystic spaces surrounded by a highly desmoplastic stroma.

Two cases showed a predominant papillary pattern accompanied with dilated and atypical changes in the epi- thelium of the collecting ducts in the adjacent renal medulla, which was the most convincing feature supporting a collecting duct origin of these tumors. Metastases, when available for examination, were histologically similar to the infiltrating part of the primary tumors. Immunocytochemically, tumor cells from all cases examined did not express keratin 10, while strong positivity to anti-keratin 5, 8, and 18 antibodies, and anti-UEL antibody was observed. The positivity to high molecular weight keratin and UEL further substantiate the diagnosis of CDC. The clinical-pathological features and protein expression of the study's 11 cases are shown in Table 1.

\section{Fezl expression}

Our results showed that Fez1 protein expression was undetectable in six of the eleven (55\%) cases. One case showed a substantial reduction of expression with $60 \%$ of the tumor cells negative, while the remaining four showed diffuse positivity for Fez1 immunostaining (Figures 1A and $1 \mathrm{~B}$ ). Overall $64 \%$ of the cases showed absence or reduction of Fez1 expression. Loss and reduction of Fez1 were correlated with a higher prevalence of lymph node metastases $(71 \%$ vs. $0 \%, \mathrm{p}=0.061)$, although the same was not true for distant metastases or tumor stage. Fez1negative tumors also tended to have higher mortality than Fez1-positive tumors. Median survival time was estimated to be 17 months for the former group, while median survival was not reached for the latter group during the course of the study (i.e., fewer than half of the patients died) $(\mathrm{p}=0.078$; Figure $2 \mathrm{~A})$. This corresponds to an estimated 5-fold increase in mortality risk for the Fez1negative CDCs (hazard ratio of 5.5).

Table I: Clinical-pathological features and protein expression.

\begin{tabular}{|c|c|c|c|c|c|c|c|c|c|c|}
\hline PZ ID & $\mathbf{T}$ & $\mathbf{N}$ & $\mathbf{M}$ & STAGEa & Fezl & Fhit & P27 & $\mathrm{Bcl} 2$ & P53 & Survival (months) \\
\hline $\mathbf{I}$ & 3 & 1 & 0 & 3 & $-*$ & - & - & - & +1 & $17^{+}$ \\
\hline 2 & 4 & 2 & 0 & 4 & - & + & - & + & - & $8^{+}$ \\
\hline 3 & 3 & 0 & 1 & 4 & - & - & - & - & - & $2^{+}$ \\
\hline 4 & 4 & 2 & I & 4 & - & + & Cyt & - & +2 & $35^{+}$ \\
\hline 5 & 3 & 0 & 0 & 3 & - & + & Cyt & - & +3 & $12^{+}$ \\
\hline 6 & 3 & 1 & 1 & 4 & - & - & - & - & - & $18^{+}$ \\
\hline 7 & 2 & 0 & 0 & 2 & + & + & - & - & - & $58^{\#}$ \\
\hline 8 & 3 & 0 & 0 & 3 & + & + & Cyt & + & +4 & $55^{\#}$ \\
\hline 9 & 3 & 0 & I & 4 & + & + & $\mathrm{Cyt}^{\wedge}$ & + & - & $8^{+}$ \\
\hline 10 & 2 & 0 & I & 4 & + & + & Cyt & - & - & $16 \#$ \\
\hline | I & 3 & 1 & 0 & 3 & - & + & Cyt & + & - & 7\# \\
\hline
\end{tabular}

\footnotetext{
a staged following the guidelines of the tumor-node-metastasis (ref 16)

* Tumor showed $60 \%$ of the cells negative for Fezl expression

$\wedge$ Nuclear p27 was also detected in this case

1,2,3,4: Showed $85,20,30,50 \%$ of the cells positive for p53 expression, respectively

+ Dead

\#Alive
} 
A

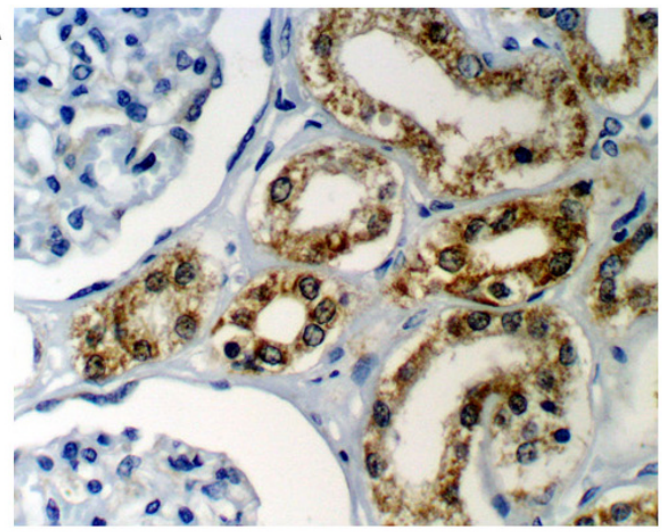

\section{C}

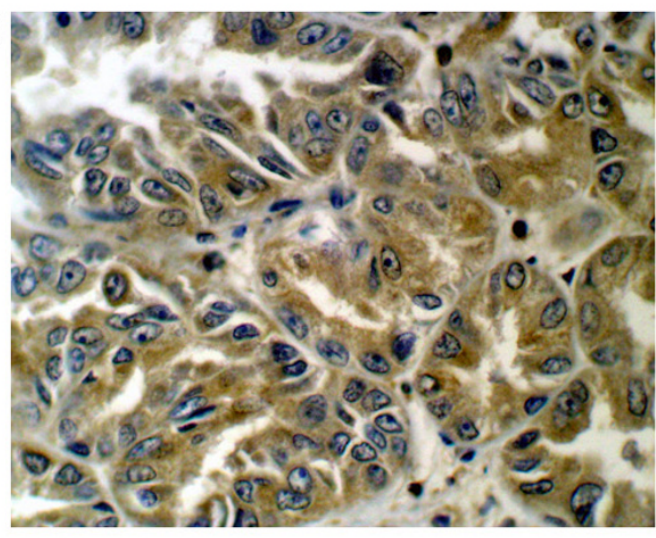

E

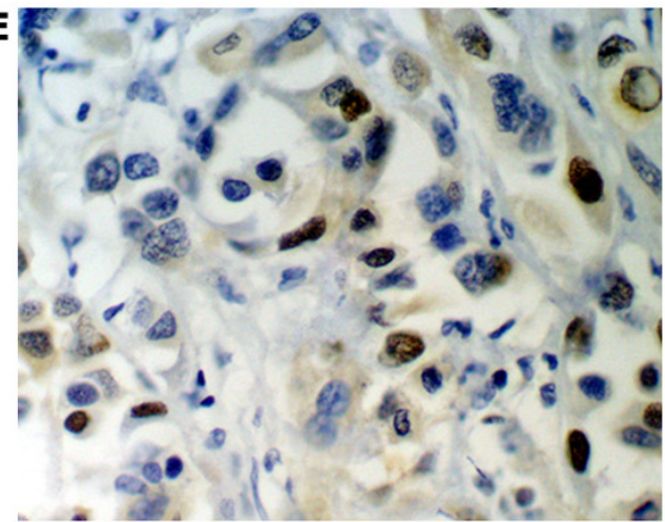

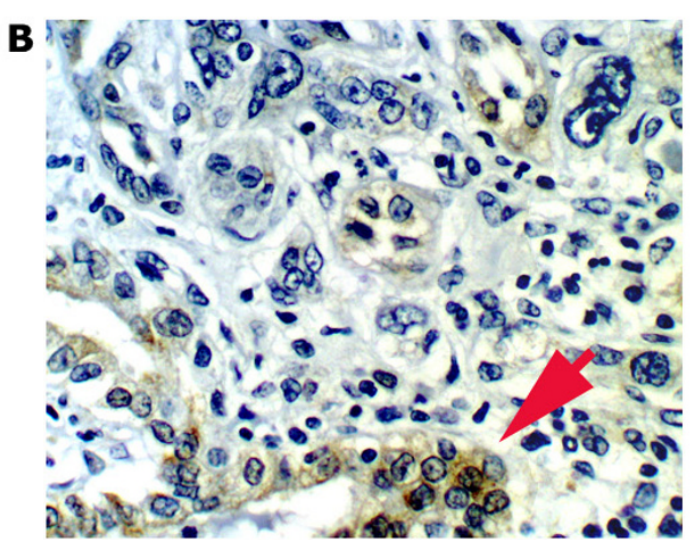
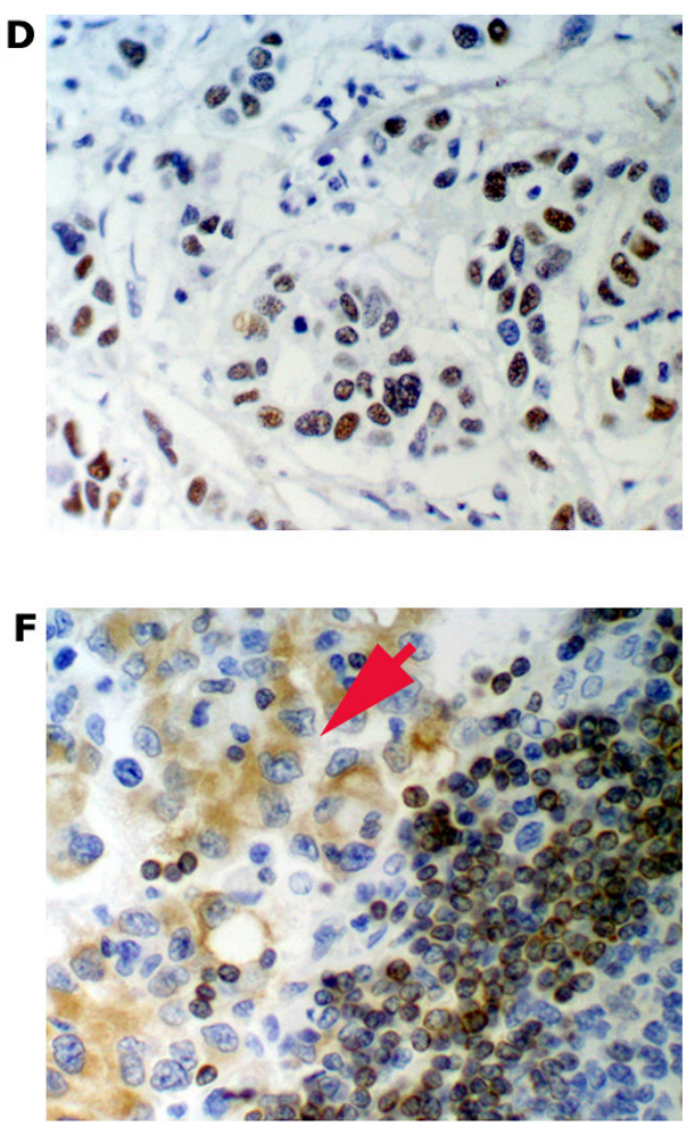

Figure I

Representative examples of immunohistochemical analysis of Fez I, Fhit, p53, p27 and bcl2 proteins in primary Bellini's duct carcinoma of the kidney. A, Normal renal parenchyma shows uniform, cytoplasmic positive staining for Fezl ( $\times 400)$. B, Fezl protein is absent in this CDC (Case I; $\times 400$ ). An adjacent dysplastic distal duct (red arrow) shows strong Fezl immunoreacticity. C, CDC section showing diffuse cytoplasmic staining for Fhit protein (Case 2; $\times 400)$. D, CDC neoplastic glands display strong nuclear immunoreaction for p53 oncoprotein (Case 5; ×400). Case 9 shows p27 immunoreactivity in both nucleus and cytoplasm (E) and bcl2 cytoplasmic immunostaining, red arrow (F) (×400). 
A

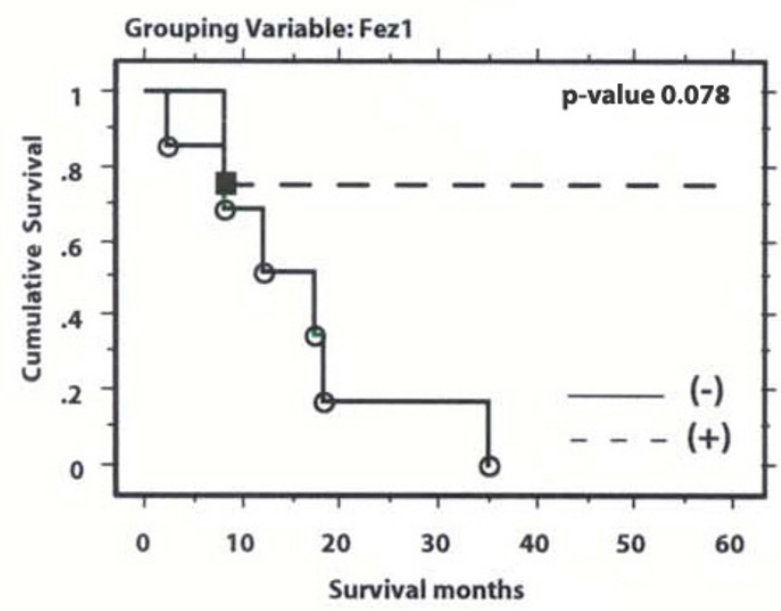

B

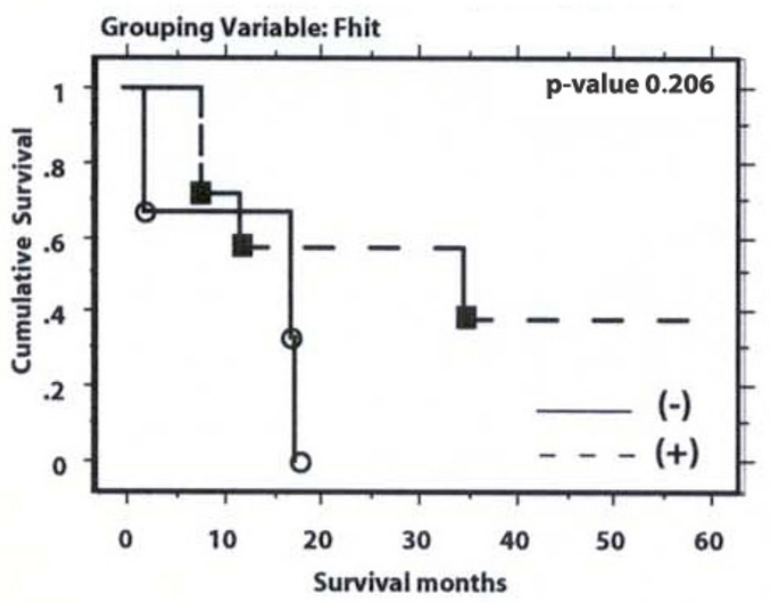

\section{Figure 2}

Kaplan-Meier survival curves and associated log-rank test $p$-values for of eleven patients with collecting duct carcinoma of the kidney based on Fezl (A), and Fhit (B) expression. (+); positive expression; (-) = negative expression; $\mathbf{Q}$ and $\mathbf{o}=$ Event times.

\section{Fhit expression}

Fhit protein was absent in three of eleven cases $(27 \%)$, and the remaining eight showed diffuse immunoreactivity (Figure 1C). Reduction of Fhit protein expression did not correlate with any of the clinicopathological features of the tumors. There was a tendency for Fhit-negative cases to have worse survival than Fhit-positive cases (median survival times of 17 vs. 35 months, respectively; hazard ratio of 2.7), although the difference was not statistically significant $(\mathrm{p}=0.206$ : Figure $2 \mathrm{~B})$.

\section{p53 expression}

p53 protein was found to be overexpressed mainly in the nucleus in four of eleven cases (36\%) (Figure 1D). One of the four positive cases showed overexpression in $85 \%$ of the cancer cells, whereas the remaining three showed $20 \%, 30 \%$ and $50 \%$ of positive cancer cells, respectively. p53 was not detectable in seven of eleven cases (63\%) as well as in the normal renal epithelium adjacent to tumor. Overexpression of p53 was not related to histologic grade, tumor stage, lymph node status, and survival.

\section{p27 expression}

Immunoreactivity for p27 was observed in the nuclei of most glomerular and tubular cells in the normal kidney. p27 immunostaining in CDC showed high variability. Protein expression was absent in five of eleven cases $(45.5 \%)$. All the remaining six carcinomas showed a high percentage ( $>40 \%$ ) of p27 positive cells. The expression of p27 protein was detected exclusively in the cytoplasm in five of the six positive cases $(90 \%)$ while a mixture of nuclear and cytoplasmic protein staining was observed in the last case (Figure 1E). Overall, we observed lack or subcellular compartmentalization of p27 in $90 \%$ of the cases. The status of p27 did not correlate to any of the clinicalpathological parameters tested.

\section{Bcl2 expression}

$\mathrm{Bcl} 2$ protein expression in $100 \%$ of the CDC tumor cells was observed in four of eleven cases (36\%) (Figure 1F), while the remaining seven (64\%) were negative. Statistical analysis did not reveal any significant correlation between $\mathrm{Bcl} 2$ expression and other clinical-pathological parameters.

Clinical-pathological features as well as immunohistochemistry results are listed in Table 1 . The proportion of marker expression ranged from 36\% (Fez1 and $\mathrm{Bcl} 2$ ) to $73 \%$ (Fhit). Marker expression tended to be positively correlated, with the correlation between Fhit and p27 being the strongest $(0.67)$, followed by that between Fhit and Fez1 and Fhit and Bcl2 (both 0.46).

\section{Discussion}

The application of the most recent molecular cytogenetic techniques revealed that renal parenchymal tumors can be classified into distinct subtypes based on the combination of specific genetic alterations [18]. The pathological and immunohistochemical description as well as the cytogenetic abnormalities support the hypothesis that 
CDC is more similar to urothelial carcinoma than to clear cell carcinoma of the kidney. Indeed, whereas allelic deletion of the short arm of chromosome 3 is considered a genetic hallmark of clear cell carcinoma, LOH at chromosomes $8 p, 9 p$, and $17 p$ has been frequently described in both transitional cell carcinoma and CDC. Here, we have reported the results of our immunohistochemical analysis of the expression of five genes (FEZ1, FHIT, P53, P27kip1, and BCL2) in a relatively large series of CDCs (eleven cases), considering the rarity of this tumor.

FEZ1/LZTS1 (leucine zipper tumor suppressor 1) is a putative tumor suppressor gene located at $8 \mathrm{p} 22$ [19]. Studies have indicated this chromosomal region is the location of an important tumor suppressor gene (TSG) [20]. $\mathrm{LOH}$ at $8 \mathrm{p}$ has been described in $50 \%$ of the CDCs studied [12], suggesting that a TSG in this region may also play a role in the development of this rare tumor. In our study, we found loss of Fez1 expression in the majority of CDCs studied and a correlation with the presence of lymph node metastasis. Furthermore, lack of Fez1 protein correlated with a poorer prognosis in $90 \%$ of patients with median survival of 17 months.

FEZ1 encodes a $67-\mathrm{kDa}$ leucine-zipper protein with a region of similarity to cAMP-dependent activated protein [19]. Mutations of FEZ1 gene have been reported in several solid tumors, including prostate, breast, esophageal, and gastric carcinomas $[17,19]$. In addition, reduced Fez1 expression is associated with high-grade transitional cell carcinoma of the bladder [21]. Recent studies have shown that the introduction of FEZ1 into Fez1 null cancer cells reduced cell growth with the accumulation of cells at late $S$ to $G_{2} / M$ phase of the cell cycle. Conversely, inhibition of Fez1 expression stimulated cells growth [22]. Furthermore, $\mathrm{LOH}$ at the chromosomal region where the FEZ1 gene lies (8p21-22) has been also associated with the invasive behavior of breast cancer [23] and with prostate cancer progression [24]. These data are consistent with an important role of FEZ1 in several human cancers including CDC.

The tumor suppressor gene FHIT maps to the short arm of chromosome 3 (3p14.2), encompasses the common FRA3B fragile region, and encodes for a protein of 16.8 $\mathrm{kDa}$, with diadenosine triphosphate hydrolase activity [25]. Reduction of Fhit protein expression as consequence of alteration of the FHIT gene has been observed by immunohistochemistry in many types of cancers $[26,27]$. Although Shoemberg et al. did not detect LOH involving chromosome 3p [12], Hadaczek et al. reported LOH at 3p in two cases of CDC [13]. The same authors described a correlation between reduced Fhit expression and $3 p$ allelic loss in renal carcinomas, particularly in CDCs [28]. While in our study Fhit inactivation does not seem to be a com- mon event in CDC, an involvement of the FHIT gene in tumorigenesis of this rare tumor cannot be excluded.

The TP53 tumor suppressor gene maps to chromosome 17 p13.1 and plays a major role in DNA transcription, cell growth, proliferation and apoptosis process [29]. In normal cells, expression of wild type p53 protein is generally below the detection level when studied by immunohistochemical method. However, p53 gene point mutations occur frequently $(22-76 \%)$ in different solid neoplasms. Mutated p53 protein, being more resistant to degradation, accumulates in the cells and can be detected by immunohistochemistry. Although an association between p53 protein overexpression and tumor stage, grade and survival has been observed in RCC [30] our data suggest that involvement of p53 alterations does not occur with the same frequency in CDC.

P27 is a member of the universal cyclin-dependent kinase inhibitor (CDKI) family. The expression of this important protein is regulated by cell to cell contact inhibition as well as by specific growth factors, such as transforming growth factor (TGF- $\beta$ ). In addition to its role as a CDKI, p27 is considered a putative tumor suppressor gene, a major regulator of drug resistance in solid tumors, and a promoter of apoptosis. p27 acts also as a safeguard against inflammatory injury and has a role in cell differentiation [31]. It has been suggested that loss of the p27 negative cell cycle regulation may contribute to oncogenesis and tumor progression in several tumor types. In renal cell carcinoma, Kamai et al. reported that low level of p27 protein was associated with tumor invasion and unfavorable prognosis, suggesting p27 as a powerful prognostic marker for survival in urinary tract cancer [32]. Masuda et al. indicated that p27 has an independent predictive prognostic value for transitional cell carcinoma of the renal pelvis [33]. Our results show that p27 loss or subcellular compartmentalization represents a frequent feature in CDCs. Previous studies have noted that cytoplasmic localization of p27 lead to an inactivation of its normal function as negative cell cycle regulator [34].

Nevertheless, we did not find statistical correlation to assess its involvement in CDC biology, possibly due to the limited number of tumors studied.

The proto-oncogene $B C L 2$, implicated in the regulation of cell death by inhibiting apoptosis, seems to be vital in normal kidney morphogenesis. In fact, Bcl2 deficient mice develop polycystic kidneys characterized by dilated proximal and distal tubules [35]. High levels of Bcl2 protein expression have been found in many different types of cancer, suggesting a possible role for $\mathrm{Bcl} 2$ deregulation of apoptosis and malignant tissue transformation. Expression of $\mathrm{Bcl} 2$ has also been associated with poor prognosis 
in patients with various cancers including prostate cancer [36]. In the present study, Bcl2 expression was not associated with any clinical-pathological variables.

Our results suggest a potential association between FEZ1 expression and CDC pathology and prognosis. No similar patterns were seen for any of the other markers studied. Even so, the statistical power of the study was limited and negative findings should not be construed as evidence that these markers are not important. Rather, a larger study would need to be carried out to further investigate their role in CDC.

\section{Conclusions}

Our results suggest that Fez1 expression may be associated to both clinical-pathological features and survival in patients with CDC. FEZ1 gene alterations may be linked to the high frequency of LOH found at 8p22, where FEZ1 resides. The lack of similar association for the other four genes studied may be due to the low statistical power of the study.

\section{Competing interests \\ None declared.}

\section{Abbreviations}

CDC, Collecting Duct Carcinoma; RCC, renal cell carcinoma; LOH, loss of heterozygosity

\section{Authors' contributions}

A.V. carried out the immunohistochemical analysis and reviewed the slides, he also contributed to the draft of the manuscript. T.P.G. was responsible for the clinical study. M.G. carried out the original histopathological diagnosis. H.I. participated in the immunohistochemical analysis and statistical analysis. E.G. participated in the immunohistochemical analysis and statistical analysis. F.P. was responsible for the clinical study. L.G.G. participated in designing the study and in drafting the manuscript. C.M.C. participated in designing the study. R.B. participated in the original design and coordination of the study, and in writing the manuscript

\section{Acknowledgements}

This work was supported partially by U.S. Public Health Service Grants to C.M.C. and by the Sidney Kimmel Foundation award to R.B. We thank Constantine Daskalakis, $\mathrm{ScD}$, of the Biostatistics Section, Thomas Jefferson University, for statistical help on the manuscript.

\section{References}

I. Jemal A, Tiwari RC, Murray T, Ghafoor A, Samuels A, Ward E, Feuer EJ, Thun MJ: Cancer statistics, 2004. CA Cancer J Clin 2004, 54:8-29.

2. Holthofer H, Miettinen A, Paasivuo R, Lehto VP, Linder E, Alfthan O, Virtanen I: Cellular origin and differentiation of renal carcinomas. A fluorescence microscopic study with kidney-specific antibodies, antiintermediate filament antibodies, and lectins. Lab lnvest 1983, 49:317-326.
3. Fleming S, Lewi $\mathrm{HJ}$ : Collecting duct carcinoma of the kidney. Histopathology 1986, 10: I |31-II41.

4. Peyromaure M, Thiounn N, Scotte F, Vieillefond A, Debre B, Oudard $\mathrm{S}$ : Collecting duct carcinoma of the kidney: a clinicopathological study of 9 cases. J Urol 2003, I70: I I38-1 I 40.

5. Dimopoulos MA, Logothetis CJ, Markowitz A, Sella A, Amato R, Ro $\mathrm{J}$ : Collecting duct carcinoma of the kidney. $\mathrm{Br} J$ Urol 1993, $71: 388-391$.

6. Mancilla-jimenez R, Stanley RJ, Blath RA: Papillary renal cell carcinoma: a clinical, radiologic, and pathologic study of 34 cases. Cancer 1976, 38:2469-2480.

7. Kennedy SM, Merino MJ, Linehan WM, Roberts JR, Robertson CN Neumann RD: Collecting duct carcinoma of the kidney. Hum Pathol 1990, $21: 449-456$.

8. Pitz S, Moll R, Storkel S, Thoenes W: Expression of intermediate filament proteins in subtypes of renal cell carcinomas and in renal oncocytomas. Distinction of two classes of renal cell tumors. Lab lnvest 1987, 56:642-653.

9. Waldherr R, Schwechheimer K: Co-expression of cytokeratin and vimentin intermediate-sized filaments in renal cell carcinomas. Comparative study of the intermediate-sized filament distribution in renal cell carcinomas and normal human kidney. Virchows Arch A Pathol Anat Histopathol 1985, 408: 15-27.

10. Fuzesi L, Cober M, Mittermayer C: Collecting duct carcinoma: cytogenetic characterization. Histopathology 1992, 21 : I55-160.

II. Gregori-Romero MA, Morell-Quadreny L, Llombart-Bosch A: Cytogenetic analysis of three primary Bellini duct carcinomas. Genes Chromosomes Cancer 1996, 15:170-172.

12. Schoenberg M, Cairns P, Brooks JD, Marshall FF, Epstein JI, Isaacs WB, Sidransky D: Frequent loss of chromosome arms 8p and I $3 q$ in collecting duct carcinoma (CDC) of the kidney. Genes Chromosomes Cancer 1995, 12:76-80.

13. Hadaczek P, Podolski J, Toloczko A, Kurzawski G, Sikorski A, Rabbitts $P$, Huebner K, Lubinski J: Losses at 3p common deletion sites in subtypes of kidney tumours: histopathological correlations. Virchows Arch 1996, 429:37-42.

14. Kovacs G, Erlandsson R, Boldog F, Ingvarsson S, Muller-Brechlin R, Klein G, Sumegi J: Consistent chromosome 3 p deletion and loss of heterozygosity in renal cell carcinoma. Proc Natl Acad Sci U S A 1988, 85:157I-1575.

15. Cavazzana AO, Prayer-Galetti T, Tirabosco R, Macciomei MC, Stella M, Lania L, Cannada-Bartoli P, Spagnoli LG, Passerini-Glazel G, Pagano $\mathrm{F}$ : Bellini duct carcinoma. A clinical and in vitro study. Eur Urol 1996, 30:340-344.

16. Sobin LH Wittekind $\mathrm{CH}$ : TNM classification of malignant tumors, 5th Ed. International Union Against Cancer (UICC) 1997, New York, John Wiley and Sons:.

17. Vecchione A, Ishii H, Shiao YH, Trapasso F, Rugge M, Tamburrino JF, Murakumo Y, Alder H, Croce CM, Baffa R: FezI/Izts I alterations in gastric carcinoma. Clin Cancer Res 200I, 7:1546-I552.

18. Velickovic M, Delahunt B, Storkel S, Grebem SK: VHL and FHIT locus loss of heterozygosity is common in all renal cancer morphotypes but differs in pattern and prognostic significance. Cancer Res 200I, 61:48I5-48I9.

19. Ishii H, Baffa R, Numata SI, Murakumo Y, Rattan S, Inoue H, Mori M, Fidanza $V$, Alder H, Croce CM: The FEZI gene at chromosome 8 p22 encodes a leucine-zipper protein, and its expression is altered in multiple human tumors. Proc Natl Acad Sci U S A 1999, 96:3928-3933.

20. Baffa R, Santoro R, Bullrich F, Mandes B, Ishii H, Croce CM: Definition and refinement of chromosome 8p regions of loss of heterozygosity in gastric cancer. Clin Cancer Res 2000, 6:1372-1377.

21. Vecchione A, Ishii H, Baldassarre G, Bassi P, Trapasso F, Alder H, Pagano F, Gomella LG, Croce CM, Baffa R: FEZI/LZTSI is downregulated in high-grade bladder cancer, and its restoration suppresses tumorigenicity in transitional cell carcinoma cells. Am J Pathol 2002, 160:1345-1352.

22. Ishii $\mathrm{H}$, Vecchione A, Murakumo $\mathrm{Y}$, Baldassarre $\mathrm{G}$, Numata $\mathrm{S}$, Trapasso F, Alder H, Baffa R, Croce CM: FEZI/LZTSI gene at 8p22 suppresses cancer cell growth and regulates mitosis. Proc Natl Acad Sci U S A 200I, 98: 10374-10379.

23. Yaremko ML, Recant WM, Westbrook CA: Loss of heterozygosity from the short arm of chromosome 8 is an early event in breast cancers. Genes Chromosomes Cancer 1995, I3:186-191. 
24. Jenkins R, Takahashi S, DeLacey K, Bergstralh E, Lieber M: Prognostic significance of allelic imbalance of chromosome arms $7 q$, $8 \mathrm{p}, 16 \mathrm{q}$, and $18 \mathrm{q}$ in stage T3NOMO prostate cancer. Genes Chromosomes Cancer 1998, 21:131-143.

25. Ohta M, Inoue H, Cotticelli MG, Kastury K, Baffa R, Palazzo J, Siprashvili Z, Mori M, McCue P, Druck T, et al.: The FHIT gene, spanning the chromosome 3pl4.2 fragile site and renal carcinomaassociated $t(3 ; 8)$ breakpoint, is abnormal in digestive tract cancers. Cell 1996, 84:587-597.

26. Vecchione A, Zanesi N, Trombetta G, French D, Visca P, Pisani T, Botti C, Croce CM, Mancini R: Cervical dysplasia, ploidy, and human papillomavirus status correlate with loss of Fhit expression. Clin Cancer Res 200I, 7:1306-13I2.

27. Baffa R, Gomella LG, Vecchione A, Bassi P, Mimori K, Sedor J, Calviello CM, Gardiman M, Minimo C, Strup SE, McCue PA, Kovatich A], Pagano F, Huebner K, Croce CM: Loss of FHIT expression in transitional cell carcinoma of the urinary bladder. Am J Pathol 2000, I 56:419-424.

28. Hadaczek P, Kovatich A, Gronwald J, Lubinski J, Huebner K, McCue PA: Loss or reduction of Fhit expression in renal neoplasias: correlation with histogenic class. Hum Pathol 1999, 30:1276-1283.

29. Gottlieb TM, Oren M: p53 in growth control and neoplasia. Biochim Biophys Acta 1996, I 287:77-102.

30. Ljungberg B, Bozoky B, Kovacs G, Stattin P, Farrelly E, Nylander K, Landberg G: p53 expression in correlation to clinical outcome in patients with renal cell carcinoma. Scand J Urol Nephrol 200I, 35:15-20.

31. Toyoshima H, Hunter T: p27, a novel inhibitor of G I cyclin-Cdk protein kinase activity, is related to p2I. Cell 1994, 78:67-74.

32. Kamai T, Takagi K, Asami H, Ito Y, Arai K, Yoshida KI: Prognostic significance of p27Kip I and Ki-67 expression in carcinoma of the renal pelvis and ureter. BJU Int 2000, 86:14-19.

33. Masuda M, Takano Y, Iki M, Makiyama K, lkeda I, Noguchi S, Hasegawa Y, Hosaka M: Cyclin-dependent kinase inhibitor p27(Kipl) expression in transitional cell carcinoma of renal pelvis and ureter. Cancer Lett 2000, I50:183-189.

34. Baldassarre G, Belletti B, Bruni P, Boccia A, Trapasso F, Pentimalli F, Barone MV, Chiappetta G, Vento MT, Spiezia S, Fusco A, Viglietto G: Overexpressed cyclin D3 contributes to retaining the growth inhibitor $\mathbf{2 7}$ in the cytoplasm of thyroid tumor cells. J Clin Invest 1999, 104:865-874.

35. Veis DJ, Sorenson CM, Shutter JR, Korsmeyer SJ: Bcl-2-deficient mice demonstrate fulminant lymphoid apoptosis, polycystic kidneys, and hypopigmented hair. Cell 1993, 75:229-240.

36. Tanji N, Yokoyama M, Sugamoto T, Takeuchi M, Terada N: Apoptosis in prostatic adenocarcinomas; a study of relationship to $\mathrm{Ki}-67$ and $\mathrm{Bcl}-2$ protein expression. Anticancer Res 1998, I8: IIII-III6.

\section{Pre-publication history}

The pre-publication history for this paper can be accessed here:

http://www.biomedcentral.com/1471-2490/4/11/prepub

\section{Publish with Bio Med Central and every scientist can read your work free of charge}

"BioMed Central will be the most significant development for disseminating the results of biomedical research in our lifetime. "

Sir Paul Nurse, Cancer Research UK

Your research papers will be:

- available free of charge to the entire biomedical community

- peer reviewed and published immediately upon acceptance

- cited in PubMed and archived on PubMed Central

- yours - you keep the copyright
BioMedcentral 